\title{
EDITORIAL
}

\section{Building bridges and crossing them: Translational research in developmental psychopathology}

\author{
DANTE CICCHETTI ${ }^{a}$ AND SHEREE L. TOTH ${ }^{b}$ \\ anstitute of Child Development, University of Minnesota; and \\ ${ }^{b}$ Mt. Hope Family Center, University of Rochester
}

Knowing is not enough; we must apply.

Willing is not enough; we must do.

\section{Goethe}

To improve the health and well-being of individuals, it has become clear that scientific discoveries must be translated into practical applications (Insel \& Fernald, 2004; Moses, Dorsey, Matheson, \& Thier, 2005). Historically, such discoveries, particularly in the health sciences, have begun at "the bench," with basic research at the molecular or cellular level progressing to the "bedside" or clinical venue. Increasingly, both basic researchers and those who are involved directly in patient care recognize that the bench-bedside approach to translational research is best conceptualized as reciprocal in nature (Cicchetti \& Hinshaw, 2002; Ialongo et al., 2006). That is, basic scientists can develop new tools for utilization with patients, and clinical researchers

Our work on this Editorial and Special Issue was partially supported by research grants from the National Institute of Drug Abuse, the National Institute of Mental Health, and the Spunk Fund, Inc.

Address correspondence and reprint requests to: Dante Cicchetti, McKnight Presidential Chair of Child Psychology and Psychiatry, Institute of Child Development, University of Minnesota, 51 E. River Road, Minneapolis, MN 55455, or Sheree L. Toth, Director, Mt. Hope Family Center, University of Rochester, 187 Edinburgh Street, Rochester, NY 14608. and clinicians can make novel assessments about the nature and progression of disease that can stimulate further basic research investigations (Zerhouni, 2005). This bidirectional process is consistent with one of the central tenets of developmental psychopathology, where knowledge on normative and atypical development is considered to be mutually informative (Cicchetti, 1993; Cicchetti \& Toth, 1998, 2006; Rutter \& Sroufe, 2000).

To begin, it is necessary to define what is meant by translational research. Of interest, a full consensus on this important definitional issue has been slow to emerge. At a National meeting on "Enhancing the Discipline of Clinical and Translational Sciences" (National Institutes of Health and National Center for Research Resources, May, 2005), the terminology of how to define clinical and translational research was reportedly discussed at length in one breakout session, with no ultimate resolution. In a Program Announcement issued by the National Institute of Neurological Disorders and Stroke designed to reduce the burden of neurological disease by encouraging the translation of research discoveries into treatments, translational research was defined as the process of applying ideas, insights, and discoveries generated through basic scientific inquiry to the treatment or prevention of human disease. Although much translational work has focused on physical as 
opposed to mental health (Smith, 2005; Waxman, 2005), efforts have been increasingly directed toward fostering similar application of scientific discoveries to decreasing the societal burden of mental illness (Gorman, 2005; Insel, 2005; Insel \& Fernald, 2004).

The impetus to conduct translational research in the behavioral sciences has emanated largely from the National Institute of Mental Health and was spurred by the recognition of the tremendous social and economic burden associated with mental illness (National Advisory Mental Health Council, 2000). It has been estimated that in the United States alone, mental illness costs more than \$148 billion in direct and indirect costs. In an international study of the indirect costs of illness and injury, mental disorders were found to account for more than $10 \%$ of the global burden of disease (Murray \& Lopez, 1996). Four mental disorders, including unipolar and bipolar depression, schizophrenia, and obsessive-compulsive disorder, ranked among the 10 leading causes of disability worldwide, with unipolar major depression leading the ranking. Furthermore, in the age range of 15-44 years, mental disorders ranked higher than all other medical diseases with respect to a measure that is a combination of years lost to premature death and disability (Insel, 2005). Among mental illnesses, unipolar depressive disorders (first), alcohol (second), and drug use disorders (fourth), bipolar disorder (sixth), and schizophrenia (eighth) all ranked in the top 10 among leading sources of disability (Insel, 2005).

In order to facilitate the translation of basic research knowledge to problems of clinical import, it is clear that increased interdisciplinary efforts are needed (Pellmar \& Eisenberg, 2000). Such interdisciplinary efforts have been repeatedly called for by developmental psychopathologists (Cicchetti, 1990, 2006; Cicchetti \& Dawson, 2002; Cicchetti \& Posner, 2005; Cicchetti \& Toth, 1991; Nelson et al., 2002; Sroufe \& Rutter, 1984). The transdisciplinary collaboration among Nelson and colleagues (2002), drawing upon advances in developmental psychology, developmental psychopathology, and developmental neuroscience, provides an excellent exemplar of how interdisciplinary research on nonhuman primates can be translated to conducting investigations on typical and atypical human development.

Although single disciplinary research has been, and will continue to be, important, both single and interdisciplinary research will be needed to understand basic mechanisms of brain and behavior and to foster the development of methods to prevent, diagnose, and treat mental illness. The National Academy of Sciences (Pellmar \& Eisenberg, 2000) defined interdisciplinary research as a cooperative effort by a team of investigators, each of whom is an expert in the utilization of different methods and concepts, and who have united in an organized manner to address a challenging problem. Within this definitional parameter, translational research was viewed as a subset of interdisciplinary research that integrates information from clinical arenas and basic research laboratories.

Despite agreement on the need to conduct interdisciplinary research and training, barriers continue to impede progress in this arena. Significant differences across disciplines with respect to terminology and perceptions must be surmounted. Often there is a belief that interdisciplinary science is second rate, a view also often shared by basic researchers about more applied sciences. The tenure process, with a focus on "independent" career trajectories and first-author publications also tends to discourage interdisciplinary collaboration. In view of the increasing specialization within fields, it is unlikely that a single researcher can master multiple areas of inquiry. However, this reality calls even more strongly for the integration of expertise across disciplines. Given the magnitude and complexity of addressing mental illness, as well as increasingly sophisticated technologies that can be applied to these problems, it is somewhat naive to expect that individuals working in isolation will be as effective as more unified efforts.

Of course, this is not to disparage single disciplinary work. In fact, investigators in single disciplinary work have contributed significantly to our understanding of basic biology and human behavior and a number of basic 
research findings have been exported into clinical arenas (Fenton, Stover, Cuthbert, Heinssen, \& Rosenfeld, 2002). For example, exposure therapies based on the research of Watson (1929) and early behaviorists are widely utilized in the treatment of anxiety disorders and posttraumatic stress disorder. Social skills training derived from Skinner's operant conditioning work (Skinner, 1938) and Bandura's social-learning theory (Bandura, 1977, 1986) have been effectively directed toward the treatment of mental illness. Research on basic attention and attentional control has been incorporated into psychotherapies designed to help patients with major depressive disorder modify their negative perceptions to develop more adaptive ways of appraising situations. Such single disciplinary efforts often provide the foundation for subsequent interdisciplinary work. As emphasized by the National Academy of Sciences (Pellmar \& Eisenberg, 2000), interdisciplinary research should arise out of a challenge that cannot be addressed by a single disciplinary approach and should not be an end to itself, but rather a necessary step in a process designed to achieve a goal.

Although the above examples illustrate the impact that basic research can have on the application of such knowledge to the treatment of mental disorders, the growth of basic research knowledge has significantly exceeded its application to clinical disorders (Fenton et al., 2002). To reduce the gap between basic and applied research, researchers who are receptive to approaches that may go beyond the boundaries and "comfort zones" of their areas of expertise are needed. To integrate areas as diverse as neuroscience, genetics, emotion, cognition, social cognition, and interpersonal processes, collaboration across disciplinary, departmental, and institutional boundaries is needed. Developmental psychopathology, an integrative scientific discipline that strives to unify contributions from multiple fields of inquiry with the goal of understanding the mutual interplay between psychopathology and normative adaptation, provides a strong framework for launching translational research (Cicchetti \& Toth, 2000, 2006; Rutter \& Sroufe, 2000).
In summary, we concur that translational research is needed to impart more scientific knowledge of genetic, neurobiological, $\operatorname{cog}$ nitive, social-cognitive, and socioemotional processes to the understanding and treatment of mental disorders. Similarly, it is important that basic research be guided by recognition that, ultimately, such research must have a clear and demonstrable impact on clinical problems. We believe that rather than an all or none approach, the conduct of translational research involves a process with various steps taken along the way. There must be a recognition and agreement that basic research needs to be conceived within a conceptual framework that understands the goal of informing future application. Such a perspective does not dictate that only research directed at treatment is appropriate. Rather, as discussed earlier, basic sciences have and will continue to exert major impacts on clinical practice. Before appropriate treatments can be developed and evaluated, there must be a clear understanding of the mechanisms and processes that initiate and maintain the developmental pathways to disease. Moreover, the discovery of the processes that contribute to at risk populations averting mental disorder can be very informative in guiding translational research and treatment development (Cicchetti, Toth, \& Rogosch, 2000; Luthar \& Cicchetti, 2000).

The contributors to this Special Issue of Development and Psychopathology share a commitment to the importance of rigorously conducted research that can be directed toward elucidating contributors to mental disorder and, ultimately, to alleviating the burden of mental illness in society. Although not all articles in this issue include explicit interdisciplinary collaborations, a receptivity to integrating knowledge across domains of knowledge is apparent in each contribution. In many ways, translational research is in its infancy. We believe that this Special Issue of Development and Psychopathology is an important step toward increasing the recognition and understanding of translational approaches, as well as toward fostering increased receptivity to designing and conducting translational research. 


\section{References}

Bandura, A. (1977). Social learning theory. Englewood Cliffs, NJ: Prentice-Hall.

Bandura, A. (1986). Social foundations of thought and action: A social cognitive theory. Englewood Cliffs, NJ: Prentice-Hall.

Cicchetti, D. (1990). A historical perspective on the discipline of developmental psychopathology. In J. Rolf, A. Masten, D. Cicchetti, K. Nuechterlein, \& S. Weintraub (Eds.), Risk and protective factors in the development of psychopathology (pp. 2-28). New York: Cambridge University Press.

Cicchetti, D. (1993). Developmental psychopathology: Reactions, reflections, projections. Developmental Review, 13, 471-502.

Cicchetti, D. (2006). Development and psychopathology. In D. Cicchetti \& D. J. Cohen (Eds.), Developmental psychopathology: Theory and method (2nd ed., Vol. 1, pp. 1-23). New York: Wiley.

Cicchetti, D., \& Dawson, G. (Eds.). (2002). Multiple levels of analysis. Development and Psychopathology, 14, 417-666.

Cicchetti, D., \& Hinshaw, S. P. (2002). Prevention and intervention science: Contributions for developmental theory [Editorial]. Development and Psychopathology, 14, 667-671.

Cicchetti, D., \& Posner, M. I. (Eds.). (2005). Integrating cognitive and affective neuroscience and developmental psychopathology. Development and Psychopathology, 17, 569-891.

Cicchetti, D., \& Toth, S. L. (1991). The making of a developmental psychopathologist. In J. Cantor, C. Spiker, \& L. Lipsitt (Eds.), Child behavior and development: Training for diversity (pp. 34-72). Norwood, NJ: Ablex.

Cicchetti, D., \& Toth, S. L. (1998). Perspectives on research and practice in developmental psychopathology. In W. Damon (Ed.), Handbook of child psychology (5th ed., Vol. 4, pp. 479-583). New York: Wiley.

Cicchetti, D., \& Toth, S. L. (Eds.). (2000). Social policy implications of research in developmental psychopathology. Development and Psychopathology, 12, 551-885.

Cicchetti, D., \& Toth, S. L. (2006). A developmental psychopathology perspective on preventive interventions with high risk children and families. In A. Renninger \& I. Sigel (Eds.), Handbook of child psychology (6th ed., pp. 497-547). New York: Wiley.

Cicchetti, D., Toth, S. L., \& Rogosch, F. A. (2000). The development of psychological wellness in maltreated children. In D. Cicchetti, J. Rappaport, I. Sandler, \& R. P. Weissberg (Eds.), The promotion of wellness in children and adolescents (pp. 394-426). Washington, DC: Child Welfare League of America Press.

Fenton, W. S., Stover, E., Cuthbert, B., Heinssen, R., \& Rosenfeld, A. (2002). Translational research: Pathway to improved practice? Psychiatric Times, XIX(6). Retrieved from http://www.psychiatrictimes.com/ p020633.html

Gorman, J. M. (Ed.). (2005). Fear and anxiety: The benefits of translational research. Washington, DC: American Psychiatric Publishing.

Ialongo, N. S., Rogosch, F. A., Cicchetti, D., Toth, S. L.
Buckley, J., Petras, H., et al. (2006). A developmental psychopathology approach to the prevention of mental health disorders. In D. Cicchetti \& D. Cohen (Eds.), Developmental psychopathology: Theory and method (2nd ed., Vol. 1, pp. 968-1019). New York: Wiley.

Insel, T. R. (2005). Developmental psychobiology for public health: A bridge for translational research. $\mathrm{De}$ velopmental Psychobiology, 47, 209-216.

Insel, T. R., \& Fernald, R. D. (2004). How the brain processes social information: Searching for the social brain. Annual Review of Neuroscience, 27, 697-722.

Luthar, S. S., \& Cicchetti, D. (2000). The construct of resilience: Implications for intervention and social policy. Development and Psychopathology, 12, 857-885.

Moses, H., III, Dorsey, E. R., Matheson, D. H. M., \& Thier, S. (2005). Financial anatomy of biomedical research. Journal of the American Medical Association, 294, 1333-1342.

Murray, C. J., \& Lopez, A. D. (Eds.). (1996). The global burden of disease: A comprehensive assessment of mortality and disability from diseases, injuries, and risk factors in 1990 and projected to 2020. Cambridge, MA: Harvard University, School of Public Health.

National Advisory Mental Health Council. (2000). Translating behavioral science into action: Report of the National Advisory Mental Health Counsel's behavioral science workgroup (No. 00-4699). Bethesda, MD National Institutes of Mental Health.

National Institutes of Mental Health, National Center for Research Resources. (2005). Proceedings of the $\mathrm{Na}$ tional Meeting on Enhancing the Discipline of Clinical and Translational Sciences. Arlington, VA: Author.

Nelson, C.A., Bloom, F. E., Cameron, J. L., Amaral, D., Dahl, R. E., \& Pine, D. (2002). An integrative, multidisciplinary approach to the study of brain-behavior relations in the context of typical and atypical development. Development and Psychopathology, 14, 1-22.

Pellmar, T. C., \& Eisenberg, L. (Eds.). (2000). Bridging disciplines in the brain, behavioral, and clinical sciences. Washington, DC: National Academy Press.

Rutter, M., \& Sroufe, L. A. (2000). Developmental psychopathology: Concepts and challenges. Development and Psychopathology, 12, 265-296.

Skinner, B. F. (1938). The behavior of organisms: An experimental analysis. New York: Appleton-CenturyCrofts.

Smith, D. J. (2005). Basic brain research shows its age. American Journal of Geriatric Psychiatry, 12, $1025-1026$.

Sroufe, L. A., \& Rutter, M. (1984). The domain of developmental psychopathology. Child Development, 55 , $17-29$.

Watson, J. B. (1929). Psychology from the standpoint of a behaviorist. Philadelphia, PA: Lippincott.

Waxman, S. (Ed.). (2005). From neuroscience to neurology: Neuroscience, molecular medicine, and the therapeutic transformation of neurology. New York: Elsevier/Academic Press.

Zerhouni, E. A. (2005). Translational and clinical science-Time for a new vision. The New England Journal of Medicine, 353, 1621-1624. 